but that high dosage is needed to affect the swelling. Their paper exemplifies methods which clinicians could use more widely for the clinical testing of potentially useful new antiinflammatory drugs.

\section{No Need for Change?}

The Minister of Health in H.M. (67) 58 has told members of hospital boards and committees that he does not accept the need for fundamental changes in methods of training nurses proposed by the Royal College of Nursing in its publication $A$ Reform of Nursing Education. ${ }^{12}$ The Minister believes that improvements can be produced by the provision of more tutors or better use of those available, by better selection of students and possibly the streaming of entrants, and by careful attention to the principles of student training.

Nurse administrators will read the form of self-examination suggested for their use somewhat glumly. Nothing is suggested that they have not often thought about before, but perhaps committees will listen with more attention to the Minister than they have to nurse advisers. In addition, hospitals will now be required to give returns of their student wastage, and, while this may be thought to amount to examining the stable door after the horse has bolted, the information ought to be available from all training schools.

The last section of the memorandum ends with suggestions for experimental schemes of nurse training. Hitherto, training schools have submitted such schemes to the General Nursing Council, which has sent those approved to the Ministry for ratification, and the Council has had many such schemes to consider. The Minister's list contains one new idea-that students might attend colleges of further education, presumably on a day-release basis, for " liberal studies."

At the same time as H.M. (67) 58 was published the General Nursing Council received from the students of a nurse-training school a letter which throws doubts on the validity of the Minister's belief that all is fundamentally well in nursing schools. Here is an extract:

\footnotetext{
"We wonder whether any of you know under what sort of conditions we are working here due to chronic shortage of staff. . . . This hospital seems to be staffed only by student nurses and a few sisters. The student nurses do not get any teaching experience on the ward due to the shortage of time and trained staff. One leaves a ward after three months' drudgery without ever being taught anything whatsoever. Does one attempt to do a procedure properly, we are very often told there is not time to do a sterile procedure. . . . Still exhausted from the previous day, we often find ourselves alone on the ward, dishing out breakfast for 28 patients, feeding many of them as well. . . Night duty follows a very similar pattern. One is put alone in charge of a 28-patient ward without previous experience of night duty, giving out drugs, or general supervision of patients."
}

The full text was published in the Nursing Times ${ }^{3}$ recently and a copy was sent to the Minister. It reminds us that nobody and no organization concerned with nurse training can be satisfied with the present position.

\footnotetext{
A Reform of Nursing Education. Royal College of Nursing, 1964. London.

arit. med. 7., 1964, 1, 1585

3 Nursing Times, 22 Septembe: 1967
}

\section{Modernizing Hospital Medicine}

One of the more depressing features of British medicine for those who believe in the N.H.S. is the antagonism between the profession and the Health Ministers. It is, therefore, all the more encouraging this week to find representatives of the two sides agreeing on the major faults in the organization of medical work in the hospital service. Just as welcome are their suggestions for reform, for these are both radical and realistic.

A joint working party of doctors and hospital administrators was set up by the Secretary of State for Scotland in 1965 with instructions to look for ways of improving efficiency in the hospital service. A little later a similar body was set up by the Ministry of Health and the Joint Consultants' Committee. Their first reports ${ }^{12}$ are summarized at page 291 of this week's B.M.F.

Fundamental to future planning for the hospital service is the knowledge that there are too few doctors and that there is no prospect of enough for at least ten years. So doctors must be used more efficiently, and their morale must be improved if they are not to emigrate. The Scottish report accepts that the discrepancy between the number of registrars and the number of potential consultant vacancies is responsible for much anxiety among junior staff, and recommends that numbers in the registrar grade should be reduced to the minimum which would allow for natural wastage and competition. The long-term solution to much of the discontent lies at this intermediate level of hospital work, where there is need for greater integration with general practice. The Scottish Working Party believes that much of the work could be done by family doctors if they could be brought into the hospitals as, say, part-time medical assistants. The report recognizes that expansion of the medical assistant grade has dangers, particularly the risk of consultant responsibility being carried by assistants-and it accepts that the present sessional rates of pay are not good enough to attract general practitioners. Such an appreciation of realities is welcome, as is the Working Party's conclusion that "these difficulties must be resolved however intractable they may seem."

Both reports agree that the tradition in hospitals of consultants having a fixed allocation of beds is inefficient and out of date. Both propose that hospitals should change over to a divisional system of staffing, similar to that widely used in North America. A division would consist of all the doctors working in one specialty-or in several specialties if they are linked in their functions. Chairmen of divisions would be appointed, and a committee formed of these chairmen or their representatives. Outside Scotland the chairman of this committee would hold a post roughly equivalent to the American chief of staff; in Scotland the position of medical superintendent would be retained.

These changes should lead to a greater exchange of ideas between medical staff, as well as promoting the more efficient use of beds, staff, and equipment. The danger is that a doctor's freedom to treat his patients as he thinks best may be eroded by pressures for the adoption of uniform regimens of management. Neither report even hints at the introduction of sanctions that could be used to force the nonconformist into obedience, though these do exist in certain American hospitals. The Scottish report states, "While we do not wish to depart from the principle that each

\footnotetext{
Organization of Medical Work in the Hospital Service in Scotland 1967. H.M.S.O. Price 6s. 3d.

First Report of the foint Working Party on the Organization of Medical Work in Hospitals, 1967. H.M.S.O. Price 2s. 9d.
} 